\title{
STUDY OF PRIMARY ENDOSCOPIC DACRYOCYSTORHINOSTOMY WITHOUT LACRIMAL STENT
}

\author{
Mubarak Khan, Sapna Parab \\ Department of Otorhinolaryngology, M.I.M.E.R. Medical College, Pune, INDIA
}

\begin{abstract}
OBJECTIVES/HYPOTHESIS: To evaluate the surgical outcome of primary endoscopic dacryocystorhinostomy (DCR) in nasolacrimal duct obstruction (NLDO) in our set up.

STUDY DESIGN: Retrospective non randomized study of consecutive 571 DCR performed in MIMER Medical College, Talegaon-Dabhade, Pune, India during January 2006 to December 2013 with a follow up period of minimum 1 year.

METHODS: Retrospective analysis of 571 consecutive primary endoscopic DCR procedures performed without stenting was done. Nasolacrimal system irrigation was used for preoperative assessment. Success was defined as absence of symptoms and patent nasolacrimal system.
\end{abstract}

RESULTS: The overall success rate was $87.39 \%(499 / 571)$.

CONCLUSIONS: Our study suggests that the surgical outcomes of primary endoscopic DCR in nasolacrimal duct obstruction are good.

Keywords: Endoscopic dacryocystorhinostomy (DCR)

\section{INTRODUCTION}

Dacryocystorhinostomy (DCR) is the treatment of choice for patients with chronic stenosis and obstruction of the nasolacrimal duct. This can be caused by chronic stenosis of the nasolacrimal duct and can be congenital or acquired. Nasolacrimal duct obstruction (NLDO) is common but is not a serious condition. Presenting symptoms include ex-

Address for correspondence:

Dr. Mubarak M Khan

Department Of Otorhinolaryngology

M.I.M.E.R. Medical College

Pune, INDIA -410507

mobile: +919822646207

fax: +912114223916

e-mail:ent.khan@gmail.com

Received: November 3, 2015

Accepted: December 1, 2015 cessive epiphora (tearing) and dacryocystitis (infection). Usually, cases have been refractory to conventional treatment such as warm compresses, massage and probing the nasal passage. The external DCR is standard treatment. Endoscopic DCR is a minimally invasive procedure performed by otorhinolaryngologists to unblock NLDO and correct other causes of decreased patency of the nasal passages. External dacryocystorhinostomy (EXT-DCR) was first described by Toti $(1,2)$ in 1904 . The endonasal approach was first introduced in 1893 by Caldwell $(3,4)$, but it was inherently limited by poor visibility of endonasal anatomy during surgery. The introduction of highresolution fiberoptic endoscopes in the late 1980s enabled adequate visualisation of the nasal cavities, and permitted minimally invasive surgery, under local anaesthesia, avoiding visible facial scarring $(5,6)$. Endonasal dacryocystorhinostomy (ENL-DCR) can be 
performed either entirely surgically (7) or with the assistance of laser to create the fistula.

A rigid endoscope is inserted into the nasal cavity to the lacrimal sac via the lacrimal duct to explore and confirm the nature of the obstruction. A decongestant is administered to clear the nasal passage first and then gauze, soaked with anaesthesia that numbs the area and constricts blood vessels, is inserted. The nasal mucous membrane is incised and removed, to allow for the creation of a window on the lacrimal sac and upper nasolacrimal duct. A portion of the lacrimal and maxilla bone is removed and using a blade, a vertical incision is made in the lacrimal sac and nasolacrimal duct. This study is carried out to evaluate the surgical outcome of primary endoscopic dacryocystorhinostomy (DCR) in nasolacrimal duct obstruction (NLDO) without nasolacrimal stent in our set up.

\section{METHODS AND MATERIALS}

Retrospective analysis of 571 from January 2006 to December 2010 with a follow up period of minimum 12 months. The patients ranged from 13 to 82 years of age. Our study consisted of 309 females and 262 males. Bilateral endoscopic dacryocystorhinostomy was done in 42 patients. In 73 patients, septoplasty was done along with endoscopic dacryocystorhinostomy. Informed consent was taken in all patients. Sac syringing was done every weekly for 1 month and thereafter 1 monthly for 6 months and thereafter at the end of 1 year.

In our study, indications for endoscopic dacryocystorhinostomy included chronic dacryocystitis (acquired and congenital), lacrimal sac mucocoele and lacrimal abscess.

All patients were operated under local anaesthesia (2 percent xylocaine with adrenaline) and adequate sedation except 29 patients who were operated under general anaesthesia.

\section{PROCEDURE OF ENDOSCOPIC DACRYOCYSTORHINOSTOMY}

Endoscopic DCR is a minimally invasive procedure used to bypass the nasolacrimal duct. The patient is positioned in a supine position with the head turned. The nose is packed with $4 \%$ xylocaine one hour before the surgery.

A Zero degree $4 \mathrm{~mm}$ Hopkins rigid endoscope is inserted into the nasal cavity to the lacrimal sac via the lacrimal duct to explore and confirm the nature of the obstruction. The middle turbinate is identified and its anterior arch is traced laterally as the maxillary line. The area in front of maxillary line is the lacrimal sac area. The sac is covered by the lacrimal bone which is removed during the surgical approach to lacrimal sac.

$2 \%$ xylocaine with adrenaline $(1: 100,000)$ (if no contraindication of adrenaline) is infiltrated into the lacrimal sac area. The lacrimal bone area is exposed and the bone is removed with a Kerrison DCR punch forceps.

The confirmation of the lacrimal sac is done by the movement of medial wall of sac in endoscopic view. The lacrimal punctum is then cannulated and the lacrimal sac is filled with saline. A vertical incision is created in the lacrimal sac with no.12 blade

This newly created stoma is enlarged. The lacrimal probe is cannulated from lower punctum of the eye and negotiated to come out from newly created stoma inside the nose to break any adhesion at opening of nasolacrimal duct near the sac. The sac syringing is done. The free flow of saline indicates successful surgery.

\section{RESULTS}

The success rate of our technique of endoscopic DCR without lacrimal stenting is $87.39 \%$ (499/571).

The success or patency of the endoscopic DCR depends on the size of the stoma. The larger the stoma created on the medial wall of lacrimal sac, the greater are the chances of success rate. The success is indicated by the smooth/ free flow of fluid during lacrimal sac syringing and the patient appreciating the fluid in the throat. Failure is indicated when there is no patency of the stoma.

Table 1. Pre-operative lacrimal drainage system abnormalities

\begin{tabular}{l|c} 
& \\
Chronic Dacryocystitis & 387 \\
Mucocele & 79 \\
Congenital Chronic Dacryocystitis & 5 \\
Mucocele and Dacryocystitis & 68 \\
Lacrimal abscess & 32 \\
TOTAL & 571 \\
\hline \hline
\end{tabular}


Table 2. Success rate

\begin{tabular}{lc} 
& \\
Asymptomatic & 434 \\
$\begin{array}{l}\text { Significant improvement } \\
\text { (no further procedure required) }\end{array}$ & 65 \\
Symptoms unchanged & 59 \\
Symptoms deteriorated & 13 \\
Total success & 499 \\
\hline
\end{tabular}

\section{DISCUSSION}

Endoscopic DCR is a well-established surgical technique with some advantages compared to the conventional external-DCR. These include limitation of tissue injury to the discrete fistula site, avoidance of a skin incision, excellent haemostasis, the ability to perform a lacrimal bypass operation on an outpatient basis, quicker patient rehabilitation, decreased overall health care expense and patients' preference $[8,9]$. Main limitations of the technique are its steep learning curve, the higher equipment cost and its contraindication in cases of severe preexisting nasal deformities or scarring and suspected lacrimal sac neoplasms (9).

ENL-DCR avoiding the use of laser is a well described procedure. Several surgical instruments have been employed to remove the bone overlying the lacrimal sac, including drills, osteotomes, curettes and rongeurs. Weidenbecher reported resolution or improvement of symptoms in $95 \%$ of the patients (6). In another study of surgical ENL-DCR results, Sprekelsen achieved good results on $96 \%$ of the operations (5). Both studies describe no major complications associated with the technique.

ENL-DCR performed under local anaesthesia is reported to be generally well tolerated by the patients (10). In our study, all operations were performed under local anaesthesia, except for $29 \mathrm{pa}$ tients who were operated under general anaesthesia. No significant discomfort was reported by any of our patients, which confirms the reported positive patients' views. Reported complications associated with ENL-DCR include per-operative or post-operative haemorrhage, punctal erosion related to silicone intubation, silicone tubing prolapse, canalicular obstruction, orbital fat herniation, orbital and subcutaneous emphysema, conjunctival fistula formation, retrobulbar haemorrhage, and transient medial rectus paresis (11). In our series, no severe per-operative or post-operative complications were encountered.

Utilising the excellent vision of the intranasal cavity afforded by the nasal endoscope, our experience shows us that the usual cause of endoscopic DCR (and conventional external DCR) failure is scarring at the nasal mucosal and submucosal level. There have been no studies performed to indicate the ideal rhinostomy size required for a functioning DCR, but studies have shown that patency is still achieved even after scarring has reduced a rhinostomy size to $1.8 \mathrm{~mm}$ (12).

As there does not seem to be any evidence of bony regrowth or bony encroachment upon the rhinostomy size, we therefore feel that the key to increasing the success rate of endoscopic DCR may lie in trying to reduce nasal mucosal scarring response and making a wide opening into the lacrimal sac.

The endoscopic approach of DCR has several advantages, including the following:

* It provides a better aesthetic result with no external scar.

* It allows a one-stage procedure to also correct associated nasal pathology that

* may be causative.

* It avoids injury to the medial canthus and/or pathologic scar formation.

* It preserves the pumping mechanism of the orbicularis oculi muscle.

* Active infection of the lacrimal system is not a contraindication to surgery.

* It is especially superior to the external approach in revision surgery.

* It is much less bloody and messy than the external approach.

* Because of the facility of the approach, the perioperative time is shorter.

* The success rate is comparable to the external approach.

\section{CONCLUSIONS}

1. The success rate of endoscopic dacryocystorhinostomy is $87.39 \%$. 
2. The success of the endoscopic dacryocystorhinostomy depends on the size of the stoma and by avoiding trauma to the nasal mucosa.

3. There were no post operative complications in our study.

\section{REFERENCES}

1. Toti A. Nuovo metodo conservatore dicura radicale delle soppurzioni croniche del sacco lacrimale (dacriocistorinostomia). Clin Mod Firenze. 1904;10:385-387.

2. Hofmann T, Lackner A, Muellner K, Luxenberger W, Wolf G. Endolacrimal KTP laser-assisted dacryocystorhinostomy. Arch Otolaryngol Head Neck Surg. 2003;129:329-332.

3. Caldwell GW. Two new operations for obstruction of the nasal duct. N Y J Med. 1893;57:581-582.

4. Allen KM, Berlin AJ. Dacryocystorhinostomy failure:association with nasolacrimal silicone intubation. Ophthalmic Surg.1989;20:486-489.

5. Sprekelsen MB, Barberan MT. Endoscopic dacryocystorhinostomy: surgical technique and results. Laryngoscope. 1996;106:187-189.

6. Weidenbecher M, Hosemann W, Buhr W. Endoscopic endonasal dacryocystorhinostomy: results in 56 patients. Ann Otol Rhinol Laryngol 1994, 103:363-367.

7. Jokinen K, Karja J. Endonasal dacryocystorhinostomy. Arch Otolaryngol. 1974;100:41-44.

8. Massaro BM, Gonnering RS, Harris GJ. Endonasal laser dacryocystorhinostomy. A new approach to nasolacrimal duct obstruction. Arch Ophthalmol. 1990;108:1172-1176.

9. Bartley GB: The pros and cons of laser dacryocystorhinostomy. Am J Ophthalmol 1994, 117:103-106.

10. Tripathi A, Lesser TH, O'Donnell NP, White S: Local anaesthetic endonasal endoscopic laser dacryocystorhinostomy: analysis of patients' acceptability and various factors affecting the success of this procedure. Eye. 2002;16:146-149.

11. Sadiq SA, Ohrlich S, Jones NS, Downes RN: Endonasal laser dacryocystorhinostomy--medium term results. Br J Ophthalmol.1997;81:1089-1092.

12. Lindberg JV, Anderson RL, Bumstead RM, Barreras R. Study of intranasal ostium external dacryocystorhinostomy. Arch Ophthalmol. 1992;100:1758-1762. 